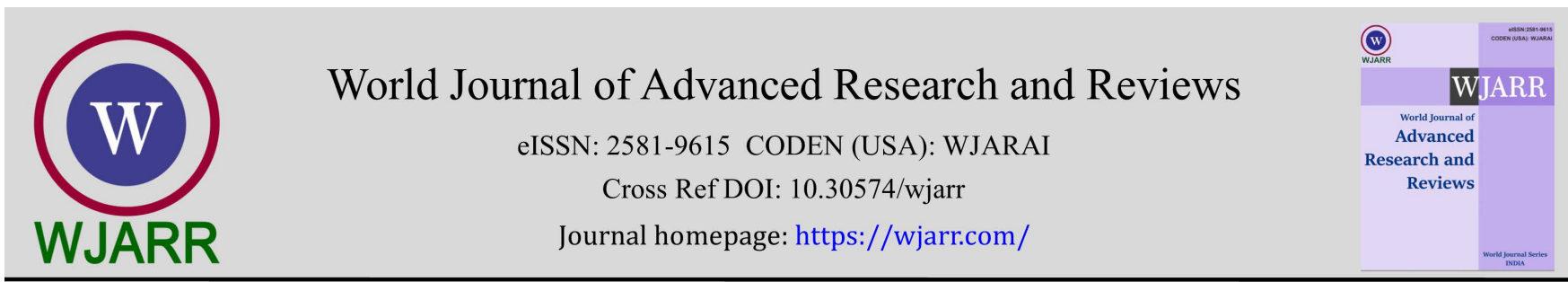

(RESEARCH ARTiClE)

\title{
Antidepressant and nootropic activity of aqueous extract of Bougainvillea glabra
}

\author{
Parikshit V. Choudhari ${ }^{1,}{ }^{*}$, Vanita G. Kanse ${ }^{2}$, A. Venkatachalam ${ }^{3}$ and Punam R. Pal ${ }^{4}$ \\ ${ }^{1}$ Faculty of Pharmacy, Pacific Academy of Higher Education and Research University, Udaipur, Rajsthan-313003. \\ 2 Oriental College of Pharmacy, Sanpada, Navi Mumbai, Maharashtra-400705. \\ 3 Pacific Academy of Higher Education and Research University, Udaipur, Rajsthan-313003. \\ ${ }^{4}$ Faculty of Pharmacy, Shri Jagdishprasad Jhabarmal Tibrewala University, Jhunjhunu, Churu Road, Vidyanagari, Churela, \\ Rajasthan-333001.
}

World Journal of Advanced Research and Reviews, 2021, 10(01), 334-339

Publication history: Received on 14 March 2021; revised on 23 April 2021; accepted on 26 April 2021

Article DOI: https://doi.org/10.30574/wjarr.2021.10.1.0163

\begin{abstract}
The aim of this analysis was to assess antidepressant \& nootropic capacity of Bougainvillea Glabra aqueous extract (BGAE). Forced swim test, tail suspension test, \& tetrabenazine mediated catalepsy \& ptosis models were used to assess BGAE's antidepressant efficacy in mice at doses of $250 \& 500 \mathrm{mg} / \mathrm{kg}$ orally. Morris water maze with elevated plus maze (EPM) was used to test nootropic behaviour. Normal medications for antidepressant \& nootropic function were imipramine $(25 \mathrm{mg} / \mathrm{kg}$ ) \& piracetam $(300 \mathrm{mg} / \mathrm{kg})$, respectively. Antioxidant assays such as DPPH \& TBARS were used to validate antidepressant \& nootropic function. When comparison to car, pre-treatment with BGAE resulted in substantial dose-dependent decrease in immobility time in both FST \& TST. (P0.005) Tetrabenazine-induced catalepsy \& ptosis were both decreased dramatically. Furthermore, in MWM \& EPM, BGAE demonstrated dose-dependent cognitive enhancing behaviour. In DPPH assay, BGAE had IC50 of $17.39 \mathrm{~g} / \mathrm{ml}$, \& in TBARS assay, it had IC50 of 398.71 $\mathrm{gm} / \mathrm{ml}$. BGAE has antidepressant \& nootropic activities that are equivalent to imipramine \& piracetam at doses of 250 $\& 500 \mathrm{mg} / \mathrm{kg}$, respectively, which may be due to its effect on neurotransmitters \& antioxidant function.
\end{abstract}

Keywords: Depression; Nootropic activity; Bougainvillea Glabra; Antioxidant

\section{Introduction}

Sadness, lack of appetite or satisfaction, feelings of low self-worth, disrupted sleep, \& decreased concentration are all symptoms of depression. Global rate of depression is consistently high, with recent WHO figures suggesting that about 350 million individuals are afflicted by depression worldwide. By 2020, World Health Organization estimates that unipolar depression will be second most common source of illness-induced disability [1]. Selected serotonin reuptake inhibitors (SSRIs), selective serotonin \& noradrenaline reuptake inhibitors (SNRIs), \& other antidepressants work by increasing catecholamine levels throughout brain. However, new treatments have drawbacks, such as adverse side effects like sedation, sexual dysfunction, \& dizziness [2]. Furthermore, there is significant body of research that depressive patients' cognitive performance is compromised [3]. Serotonin (5-HT) depletion in hippocampus, cortex, \& thalamus, which are densely innervated by serotonergic \& cholinergic neurons, may cause cognitive dysfunction. Tricyclic antidepressants can also exacerbate dementia due to their anti-cholinergic effects [4]. Plants will therefore act as potential pool of experimental antidepressant medications owing to side effects of existing antidepressants \& relatively untapped wealth of natural capital. Several ayurvedic plants have since been tested for antidepressant properties. Many of these species, such as Withania somnifera \& Celastrus paniculatus [5,] have shown promise in preclinical \& clinical trials. Many plants have been shown to have nootropic function, but only handful have been found to have both antidepressant \& nootropic properties, such as Piperin from Piper longum \& Piper nigrum. Plant IT is

\footnotetext{
* Corresponding author: Parikshit V. Choudhari

Reserach scholar, faculty of pharmacy, pacific academy of higher education and research university, udaipur, rajsthan-313003.
} 
spreading shrub that grows in India \& belongs to Fabaceae tribe. Its efficacy in treating asthma, splenomegaly, skin disorders, \& as trichogenous agent has been recorded in traditional medical systems [7, 8]. Plant contains indicaine, as well as flavonoids such as apigenin, kaempferol, luteolin, \& quercetin [8], \& has been confirmed to have anticancer, antidiabetic, \& antidyslipidaemic properties. Its putative neuropharmacological effects, mostly antiepileptic activity, have been documented. In Parkinson's disease, compound called SF-6, isolated from IT, was recently reported to have beneficial effects [9]. However, there have been no records on its antidepressant or nootropic impact. As result, current research was carried out to determine antidepressant \& nootropic efficacy of Bougainvillea Glabra aqueous extract.

\section{Material and methods}

\subsection{Animals}

For research, Swiss albino mice of either sex (20-25 g) were used. animals were housed in groups of six in polypropylene cages \& fed standard pelleted diet \& water ad libitum in photoperiod of $12 \mathrm{hr} / 12 \mathrm{hr}$ light \& dark cycle at $2520 \mathrm{C}$. All of tests took place in laboratory between hours of 9:00 a.m. \& 16:00 p.m. Institutional Animal Ethics Committee accepted experimental procedures.

\subsection{Chemicals}

(Depsonil Imipramine®, Piramal); Sarabhai (Revocon Tetrabenazine ${ }$ Pharmaceutical Sun, Industries); Scopolamine butyl bromide (Buscopan $®$, German Remedies Ltd.); Piracetam (Nootropil®- UCB India Pvt Ltd.) were among drugs used in study. Sigma Chemicals \& Sisco Research Lab Ltd. provided diphenyl, 2-picryl hydrazyl (DPPH) \& thiobarbaturic acid, respectively. Study's other solvents \& chemicals were of analytical grade. Aqueous extract was prepared with distilled water.

\subsection{Farm content collection}

IT leaves were purchased in bulk from nearby market. IT leaves were washed in distilled water, dried in hot air oven at 500 degrees Celsius, powdered in mixer grinder, \& placed in tightly sealed jar. Dr. Ganesh Iyer, botanist at Mumbai's Ruia College of Arts \& Science, confirmed leaves' identity.

\subsection{Extract preparation}

Defatted dried powdered leaves were collected with water using Soxhlet apparatus after being defatted with Petroleum ether $\left(60-80^{\circ} \mathrm{C}\right)$. Extract was dried at 50 degrees in hot air oven, \& dried extract was used for further research. In purified water, aqueous extract for oral administration was made with 0.2 percent NaCMC as suspending agent.

\subsection{Phytochemical screening}

BGAE was screened for flavonoids, glycosides, saponins, \& alkaloids using phytochemical method [10].

\subsection{Acute oral toxicology study}

An acute oral toxicity analysis of BGAE in mice was carried out in compliance with OECD guideline no. 423. Extract was found to be healthy up to dosage of $2000 \mathrm{mg} / \mathrm{kg}$, so $250 \mathrm{mg} / \mathrm{kg} \& 500 \mathrm{mg} / \mathrm{kg}$ doses were selected for in vivo pharmacological testing.

\subsection{Group therapy}

The below were care groups:

Group I: Mice received 0.2\% Na CMC orally, which served as vehicle Control

Group II: Mice were treated with BGAE orally $(250 \mathrm{mg} / \mathrm{kg})$

Group III: Mice were treated with BGAE orally $(500 \mathrm{mg} / \mathrm{kg})$

Group IV: Mice were treated with Imipramine orally $(25 \mathrm{mg} / \mathrm{kg}$ ) which served as Positive Control

The mice were split into four classes $(n=6)$ \& given 14-day pre-treatment prior to experiment. Instead of imipramine, mice were given Piracetam $(300 \mathrm{mg} / \mathrm{kg}$ ) orally as supportive control for nootropic behaviour.

\subsection{Antidepressant properties}

The models of forced swim test, tail suspension test, \& tetrabenazine mediated ptosis \& catalepsy was used in antidepressant action trials. 


\subsection{Forced swim test}

For purposes of experiment, FST stated by Porsolt et al [11] was slightly changed. Each mouse was mounted in glass cylinder (height $30 \mathrm{~cm}$, diameter $22.5 \mathrm{~cm}$ ) filled with $15 \mathrm{~cm}$ of $25^{\circ} \mathrm{C}$ water. Animals were pre-screened day before by positioning them separately in glass cylinder filled with water. Immobility reaches plateau after 5-6 minutes, with mice remaining immobile for around $80 \%$ of time. Mice were removed from water after 15 minutes $\&$ allowed to dry before being returned to their home cages. Medications were sent out 60 minutes before test on day of trial. Mice were independently put in water-filled glass cylinder again, \& time of immobility was reported over last four minutes of sixminute examination. When mouse floats motionless or makes only motions needed to hold its head above water's surface, it is called immobile. After each test, water was adjusted.

\subsection{Tail suspension test}

TST was done using Steru et al [12] process, which is basic method for measuring antidepressants. Mice were suspended in test by adhesive tape placed $1 \mathrm{~cm}$ from tip of their tails on edge of shelf $58 \mathrm{~cm}$ above tabletop. Length of immobility was measured over 5-minute cycle. When mice hung motionless \& passively, they were presumed to be immobile.

\subsection{Assessment of nootropic behaviour}

The elevated plus maze test \& Morris water maze test were used in nootropic behaviour tests.

\subsection{Elevated as well as maze test}

Two open arms $50 \times 10 \times 40 \mathrm{~cm} \&$ two closed arms of same proportions with open roof facing each other made up elevated plus maze apparatus used in research. Labyrinth was placed 50 centimetres off ground. Mice were positioned separately at end of each of open arms 60 minutes after oral administration of either vehicle or test drug, \& time taken by animal to pass from open to closed arm (transfer latency) was recorded on first day. Transfer delay was measured from moment animal was mounted on open arm to time all four legs were within sealed limbs. 24 hours after first dose, transfer latency was measured again. First \& second day's TL acted as acquisition \& retrieval criteria, respectively [14].

\subsection{Morris water mazz test}

The experimental classes used in MWM for spatial \& working memory tests were similar to those used in elevated plus maze. MWM was made up of huge water tank $(48 \mathrm{~cm} \times 28 \mathrm{~cm} \times 18 \mathrm{~cm})$ filled with water that had been tainted with milk to make it opaque. Water produces homogeneous intramaze environment, which removes olfactory interference. Water-resistant rectangular escape platform $(7 \times 7 \mathrm{~cm})$ was designed \& covered with material that helps animal to stay on top when submerged. Platform was $10 \mathrm{~cm}$ tall, allowing it to be submerged $2 \mathrm{~cm}$ below water's surface. Water was kept at steady temperature of $26^{\circ} \mathrm{C}[15]$.

\subsection{Spatial memoey test}

The mice were given drugs orally, and after 60 minutes, they were placed on training schedule that involved swimming in MWM \& discovering underwater secret base. For two more days, this process was performed at 24-hour interval until each animal had minimum time span to enter submerged surface in tank. After fourth day of preparation, both participants were given scopolamine butyl bromide. After 30 minutes, they were given test extract/standard \& checked for spatial memory for another 90 minutes. Mice with memory problems took longer to get to board.

\section{Results}

BGAE included glycosides, saponins, tannins, \& flavonoids, according to phytochemical analysis. As comparison to vehicle control group, BGAE $250 \mathrm{mg} / \mathrm{kg}, 500 \mathrm{mg} / \mathrm{kg}$, \& Imipramine treated groups showed substantial decrease in immobility duration, meaning that systemic administration of BGAE is successful in inducing antidepressant-like effect in FST \& TST (Figure No. 1) There was also decrease in severity of tetrabenazine-induced ptosis \& catalepsy in mice (Table No. 1). Pre-treatment with BGAE (250 mg/kg p.o. \& $500 \mathrm{mg} / \mathrm{kg}$ p.o.) decreased transition duration in EPM test, suggesting that it has cognition-enhancing ability. When opposed to vehicle regulation (Table No.2).

BGAE increased MWM's spatial \& working memory capacity in baseline \& scopolamine-impaired conditions (Table No.3), bolstering evidence of its nootropic ability. These findings were similar to those of piracetam-treated group. 


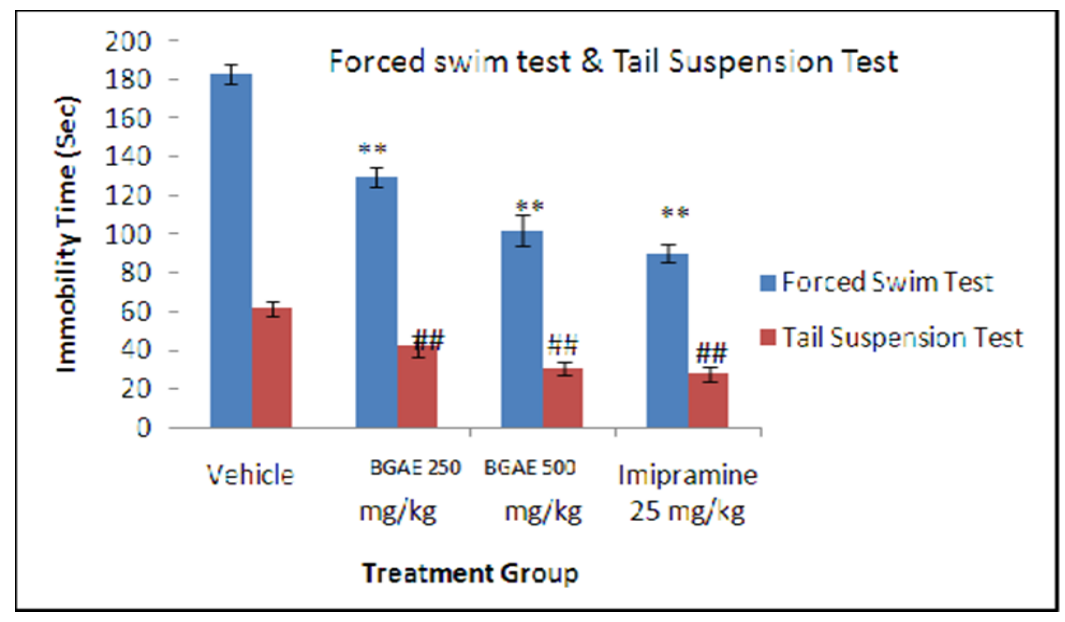

Figure 1 Effect of BGAE on Immobility time in FST \& TST.

Table 1 Effect of BGAE on Degree of Tetrabenazine induced catalepsy \& ptosis in mice (Scores).

\begin{tabular}{|l|l|l|l|}
\hline S. No. & Treatment Group & Scores of catalepsy & Scores of ptosis \\
\hline 1 & Vehicle control & $5+0.04$ & $2.83+0.31$ \\
\hline 2 & BGAE $250 \mathrm{mg} / \mathrm{kg}$ p.o & $4.3+0.1^{*}$ & $1.3+0.47^{* *}$ \\
\hline 3 & BGAE $500 \mathrm{mg} / \mathrm{kg}$ p.o & $3.45+025^{* *}$ & $1.65+0.15^{*}$ \\
\hline 4 & Positive control & $4.25+0.23^{*}$ & $1+0.21^{* *}$ \\
\hline
\end{tabular}

$\mathrm{N}=6$, Values are Mean S.E.M., *P 0.05, **P 0.01, as opposed to vehicle control category using one-way ANOVA \& DUNNETT'S Comparison Test.

Table 2 Effect of BGAE on Transfer latency using Elevated plus maze model.

\begin{tabular}{|l|l|l|}
\hline Treatment Group & \multicolumn{2}{|c|}{ Time to reach open arm (sec) } \\
\hline & Day 0 & Day 1 \\
\hline Vehicle Control & $26 \pm 3.39$ & $21.8 \pm 2.28$ \\
\hline BGAE $250-\mathrm{mg} / \mathrm{kg}$ p.o. & $31 \pm 7.69$ & $14.2 \pm 2.03^{*}$ \\
\hline BGAE 500-mg/kg p.o. & $21 \pm 4.24$ & $10.52 \pm 1.19^{*}$ \\
\hline $\begin{array}{l}\text { Positive control } \\
\text { (Piracetam 300 mg/ kg p.o) }\end{array}$ & $23.2 \pm 5.52$ & $8.73 \pm 1.54^{* *}$ \\
\hline
\end{tabular}

Table 3 Effect of BGAE on Scopolamine Induced Spatial Memory Impairment.

\begin{tabular}{|c|c|c|c|c|c|}
\hline \multirow[t]{2}{*}{ Treatment } & \multicolumn{5}{|c|}{ Latency to reach platform in sec } \\
\hline & Day 0 & Day 1 & Day 2 & Day 4\# & Day 5 \\
\hline Control & $10.7 \pm 0.93$ & $8.43 \pm 0.12$ & $7.74 \pm 0.8$ & $7.93 \pm 0.63$ & $9.79 \pm 0.72$ \\
\hline BGAE $250 \mathrm{mg} / \mathrm{kg}$ p.o & $8.46 \pm 0.37$ & $7.48 \pm 0.58$ & $2.95 \pm 0.92^{* *}$ & $3.89 \pm 1.24^{* *}$ & $3.89 \pm 0.42^{* *}$ \\
\hline BGAE 500 mg/kg p.o & $9.59 \pm 0.89$ & $7.36 \pm 0.48$ & $3.6 \pm 0.55^{* *}$ & $4.52 \pm 1.72^{* *}$ & $2.96 \pm 0.54^{* *}$ \\
\hline $\begin{array}{l}\text { Positive control Piracetam } 300 \\
\mathrm{mg} / \mathrm{kg} \text { p.o }\end{array}$ & $8.67 \pm 0.67$ & $7.31 \pm 0.48$ & $3.92 \pm 0.91$ & $3.32 \pm 0.42^{* *}$ & $2.45 \pm 1.08^{* *}$ \\
\hline
\end{tabular}
animals were given scopolamine $(2 \mathrm{mg} / \mathrm{kg}$ i.p.) 


\section{Discussion}

Depression is related to reduced quality of life, increased morbidity \& death, \& diminished comprehension. Changes in brain monoaminergic transmission (e.g., 5-Hydroxytryptamine, Norepinephrine, Dopamine), abnormalities in neurotransmitter receptor function (e.g., Adenylyl Cyclase-cAMP pathway), dysregulation of hypothalamic pituitary adrenal axis (cortisol), \& increased proinflammatory cytokines. Rodents' immobility in FST \& TST when faced with inevitable \& inescapable tension has been hypothesised to mirror depressive disorders in humans. We show conclusively in this study that BGAE $250 \mathrm{mg} / \mathrm{kg} \& 500 \mathrm{mg} / \mathrm{kg}$ given orally induce antidepressant-like effects in FST \& TST after two weeks of therapy, comparable to normal medication Imipramine (P values 0.01). However, in behavioural despair test, false positive or negative outcome may be observed due to improved or reduced locomotor function due to psychostimulating effects of antidepressants. Activity cage test was used to rule out likelihood that reduction in immobility duration elicited by treatment was due to improved locomotor activity. At doses of BGAE $250 \mathrm{mg} / \mathrm{kg} \& 500$ $\mathrm{mg} / \mathrm{kg}$ used in this research, no major differences in locomotor behaviour in mice were found. BGAE's antidepressantlike effect was not attributed to improved locomotory function, as previously thought. Furthermore, fact that BGAE effectively reversed tetrabenazine-induced ptosis \& catalepsy in mice indicates that its antidepressant ability is attributed to rise in catecholamine levels, since tetrabenazine depletes catecholamine levels substantially. Flavonoids, tannins, \& saponins were found in abundance in BGAE phytoconstituents. Flavonoids found in IT, such as apigenin, quercetin, \& kaempferol, have been shown to have significant antioxidant effects as well as antidepressant properties [21]. IT contains significant quantities of conjugated indoxyl, precursor of isatin, indole derivative, according to literature [22]. Isatin is naturally occurring substance that inhibits MAO [23]. MAO inhibitory action of isatin can contribute to increase in neurotransmitter levels, which are reduced in depression.

\section{Conclusion}

Finally, at doses of 250 \& $500 \mathrm{mg} / \mathrm{kg}$, BGAE \& BGAE exhibit antidepressant \& nootropic activities in pretreated mice, indicating that they could be effective in treatment of depression-related cognitive disability. To evoke exact mechanism of action, further study is required to classify phytoconstituents responsible for these events, as well as biochemical estimations of neurotransmitters involved in antidepressant \& nootropic activities of BGAE.

\section{Compliance with ethical standards}

\section{Disclosure of conflict of interest}

All authors declare that they have no conflict of interest.

\section{References}

[1] Shoeb A, Chowta M, Pallempatti G, Rai A, Singh A. Evaluation of antidepressant activity of vanillin in mice. Indian J of Pharmacology. 2013; 45:141-4.

[2] Jon Nash, David Nutt. Antidepressants. J Psychiatry. 2007; 6(7): 289-94.

[3] Diana Byrd Burt, Mary Jo Zembar. Depression \& Memory Impairment: A Meta-Analysis of Association, Its Pattern, \& Specificity. J Psychopharmacol Bull. 1995; 117(2): 285-305.

[4] Ramanathan M, SN Ashok Kumar, B Suresh. Evaluation of cognitive function of fluoxetine, sertaline \& tianeptine in isolation \& chronic unpredictable stress. Indian J Exp Biol. 2003; 41: 1269-72.

[5] Singh RH, Mishra LC. Psychiatric Disorders. In: Scientific Basis for Ayurvedic Therapies. J USA CRC Press. 2003: 439-51.

[6] Singh A, Duggal S. Piperine-Review of advances in Pharmacology. Int J of Pharm Sci \& Nanotechnology. 2009; 2(3): 615-20.

[7] Warrier PK, Nambiar VPK. C Ramankatty. In: Indian Medicinal Plants. Chennai: Orient Longman Private Limited. 2007; 3: 210.

[8] Saraswathi Motamarri N, Karthikeyan M, Rajasekar S, Gopal V. Bougainvillea Glabra Linn-A Psychopharmacological Review. Int J of Res in Pharm \& Biomedical Sci. 2012; 3(1): 164-9. 
[9] Spandana Rajendra Kopalli, Sushruta Kopalla, Ki Young Shin, Su-Jin Noh, Qinghao Jin, and Bang Yeon Hwang et al. SF-6 attenuates 6-hydroxydopamine-induced neurotoxicity: An in vitro \& in vivo investigation in experimental models of Parkinson's disease. J Ethnopharmacol. 2012; 143: 686-94.

[10] Khandelwal. Preliminary Phytochemical Screening. In: Practical Pharmacognosy 3rded. Pune: Nirali Prakashan. 1996; 149-55.

[11] Porsolt RD, Bertin A, Jalfre M. Behavioral despair in mice: A primary screening test for antidepressants. J Archives Int de Pharmacodynamie ET de Therapie. 1977; 229: 327-36.

[12] Steru L, Chermat R, Thierry B, Simon P. tail suspension test: A new method for screening antidepressants in mice. J Psychopharmacol. 1985; 85(3): 367-70.

[13] Vogel GH. Psychotropic \& Neurotropic activity, In Drug discovery \& Evaluation-Pharmacological assays, 2nd ed. Germany: Springer publication. 2002; 568.

[14] Mrugaya P Kulkarni, Archana R Juvekar. Effects of Alstonia scholaris (Linn.) R.Br on stress \& cognition in mice. Indian J Exp Biol. 2008; 47: 47-52.

[15] Annapurna V, Rama Krishna K, Murali Krishna V, Krishna Kumar, KB Prasad. Studies on Nootropic activity of Ramipril \& Losartan on Scopolamine-induced amnesia in Rats. Indian J Pharm Sci. 2004; 66(1): 31-5.

[16] Ketkee Deshmukh, Purnima Amin. Meltlets of Soy Isoflavones: Process optimization \& Effect of Extrusion Spheronization Process Parameters on Antioxidant activity. Indian J Pharm Sci. 2013; 75(4): 450-56.

[17] Hiroshi Ohkawa, Nobuko Ohishi, Kunio Yagi. Assay for Lipid Peroxides in Animal Tissues by Thiobarbaturic Acid Reaction. J Anal Biochem. 1979; 95: 351-8.

[18] Guilherme A, Behr José CF, Moreira Benicio N. Frey. Preclinical \& clinical evidence of Antioxidant effects of Antidepressant agents: Implications for pathophysiology of Major Depressive disorder. Oxidative Medicine \& Cellular Longevity. 2012; 1 .

[19] Ann Gardner, Richard G. Boles. Beyond serotonin hypothesis: Mitochondria, inflammation \& neurodegeneration in major depression \& affective spectrum disorders. J Prog Neuropsychopharmacol Biol Psychiatry. 2011; 35: 730-43.

[20] Jingshu Liu, Wei Qiao, Yi Yang, Liyan Ren, Yan Sun, Shaoxun Wang. Antidepressant-like effect of ethanolic extract from Suanzaorenhehua formula in mice models of depression. J Ethnopharmacol. 2012; 141: $257-64$.

[21] Li-Tao Yi, Jian-Mei Li, Yu-Cheng Li, Ying Pan, Qun Xu, Ling-Dong Kong. Antidepressant-like behavioral \& neurochemical effects of citrus-associated chemical apigenin. J Life Sci. 2008; 82: 741-51.

[22] Warjeet S Laitonjam, Sujata D. Wangkheirakpam. Comparative study of major components of indigo dye obtained from Strobilanthes flaccidifolius Nees. \& Bougainvillea Glabra Linn. Int J Plant Physiol Biochem. 2011; 3(7): 10816.

[23] Surendra Nath Pandeya, Sivakumar Smitha, Mayank Jyoti, Seshalah Krishnan Sridhar. Biological activities of isatin \& its derivatives. J Acta Pharm. 2005; 55: 27-46.

[24] Ayesha Zafir, Anjum Ara, Naheed Banu. In vivo antioxidant status: A putative target of antidepressant action. J Prog Neuropsychopharmacol Biol Psychiatry. 2009; 33: 220-28.

[25] Giselli Scaini, Brena P. Teodorak, Isabela C. Jeremias, Meline O. Morais, Francielle Mina, Diogo Dominguini et al. Antioxidant administration prevents memory impairment in animal model of maple syrup urine disease. J Behav Brain Res. 2012; 231(1): 92-6. 